\title{
Vacancy- and acceptor-H complexes in InP
}

\author{
C P Ewels $\uparrow$, S Öberg $\ddagger$, R Jones $\dagger$, B Pajot $\oint$ and P R Briddon $\|$ \\ † Department of Physics, University of Exeter, Exeter EX4 4QL, UK \\ $\$$ Department of Mathematics, University of Luleå, Luleå, S95187, Sweden \\ $\S$ Groupe de Physique des Solides, Universite Paris VII, 2 place Jussieu, \\ 75251 Paris Cédex 05, France \\ || Department of Physics, University of Newcastle, Newcastle NE1 7RU, UK
}

Received 20 November 1995, accepted for publication 3 January 1996

\begin{abstract}
It has been suggested that iron in InP is compensated by a donor, related to the $2316 \mathrm{~cm}^{-1}$ local vibrational mode and previously assigned to the fully hydrogenated indium vacancy, $\mathrm{V}_{\mathrm{In}} \mathrm{H}_{4}$. Using AIMPRO, an ab initio local density functional cluster code, we find that $\mathrm{V}_{\mathrm{In}} \mathrm{H}_{4}$ acts as a single shallow donor. It has a triplet vibrational mode at around this value, consistent with this assignment. We also analyse the other hydrogenated vacancies $\mathrm{V}_{\mathrm{In}} \mathrm{H}_{n}, n=1,3$, and determine their structure, vibrational modes, and charge states. Substitutional group II impurities also act as acceptors in InP, but can be passivated by hydrogen. We investigate the passivation of beryllium by hydrogen and find that the hydrogen sits at a bond-centred site and is bonded to its phosphorus neighbour. Its calculated vibrational modes are in good agreement with experiment.
\end{abstract}

\section{Introduction}

There is great interest in the electrical effects associated with heavy iron doping of InP. Iron doping is used to produce mid-gap levels, allowing the use of InP as a semiinsulating substrate $[1,2]$. However, Fe has many unusual properties in InP which are not yet fully understood. In particular, the charge compensation mechanism of iron has not yet been fully explained [3].

It is known that in InP:Fe, the $\mathrm{Fe}$ substitutes for In and primarily adopts the neutral $\mathrm{Fe}_{\mathrm{In}}^{3+}$ state (labelled $3+$ to denote its oxidation state). However, some of the iron is compensated, forming $\mathrm{Fe}_{\mathrm{In}}^{2+}$, and metallic donor defects are not present in sufficiently high concentrations to account for this. Therefore it has been proposed that another donor must be present; however, its identity is not established. Recent work has shown a correlation between the intensity of the $2316 \mathrm{~cm}^{-1} \mathrm{LVM}$ and the $\mathrm{Fe}_{\mathrm{In}}^{3+}$ concentration [3], suggesting that this defect could be the unknown donor.

When InP is grown by the LEC method using wet boric oxide as the encapsulant, the water vapour dissociates and hydrogen is incorporated into the material. The most intense $\mathrm{H}$-related mode in as-grown crystals occurs at $2316 \mathrm{~cm}^{-1}$ (found in InP:Fe as well as in crystals without $\mathrm{Fe}$ ), and has been associated with $\mathrm{V}_{\mathrm{In}} \mathrm{H}_{4}$ [4].

This assignment has been made for several reasons. Uniaxial stress measurements show the centre to have $T_{d}$ symmetry [4], consistently with $\mathrm{V}_{\mathrm{In}} \mathrm{H}_{4}$. The LVM lies close to that of other P-H-related modes, and this is consistent with results obtained for $\mathrm{VH}_{4}$ in $\mathrm{Si}$ [5]. The defect can be created by proton irradiation [6], which also leads to the creation of the required In vacancies.
H/D mixed defects have not been observed on mixed $\mathrm{H}^{+} / \mathrm{D}^{+}$implantation because the signal-to-noise ratio of published spectra [6] is not high enough, and the FWHPs of the proton- and deuteron-induced LVMs are too broad for the individual components to be resolvable. This last point is probably the origin of the apparent decrease in intensity of the $2316 \mathrm{~cm}^{-1}$ line reported for mixed implantation, since there are several components near $2316 \mathrm{~cm}^{-1}$. The inverse is observed for the LVM at $2202 \mathrm{~cm}^{-1}$ assigned to $\mathrm{V}_{\mathrm{In}} \mathrm{H}$, and this contrasting result also supports the assignment.

Other LVMs in SI InP include $\mathrm{H}$-acceptor modes (mainly $(\mathrm{Zn}, \mathrm{H})$ ) due to inadvertent contamination, as well as other LVMs whose origin is not clear. In slightly ntype InP:Fe, the $(\mathrm{Zn}, \mathrm{H}) \mathrm{LVM}$ is not observed, but another LVM at $2285 \mathrm{~cm}^{-1}$ is always observed. Annealing of LEC InP produces LVMs attributed to partially hydrogenated vacancies, but these are much lower in intensity than the line at $2316 \mathrm{~cm}^{-1}$.

There has been no theoretical examination of these defects performed to date. We therefore investigate the structure, local vibrational modes and charge states of a range of hydrogenated vacancies, $\mathrm{V}_{\mathrm{In}} \mathrm{H}_{n}, n=0,4$.

Group II residual impurities are normally present in $\mathrm{InP}$ at low concentrations. They are known to act as acceptors, producing shallow levels in the gap [7]. It has been observed that the presence of hydrogen is able to passivate these impurities, and it is only recently that there have been attempts to fully understand this process $[4,8]$.

Experimental investigations of $\mathrm{H}-$ and D-plasmapassivated $\mathrm{Be}, \mathrm{Mg}, \mathrm{Cd}$ and $\mathrm{Zn}$ have been performed [4]. 
Infrared absorption studies show hydrogen local vibrational modes (LVMs) which lie in the frequency range where $\mathrm{P}-$ $\mathrm{H}$ stretch modes are expected $\left(\approx 2200-2300 \mathrm{~cm}^{-1}\right)$. This suggests that hydrogen bonds to phosphorus atoms in the lattice instead of the acceptor impurities.

Uniaxial stress measurements show that these acceptorhydrogen defects have $\mathrm{C}_{3 \mathrm{v}}$ symmetry [4]. Therefore, since these group II acceptors are known to substitute for indium, hydrogen must lie somewhere along the $\langle 111\rangle$ acceptor$\mathrm{P}$ direction. Passivation with a mixed $\mathrm{H}, \mathrm{D}$ plasma produces no peak splitting, suggesting that there is only one hydrogen atom present in each defect. It was suggested that passivation occurred through a chemical recombination, allowing a lower coordination for the group II acceptor atoms and tying up the resultant dangling bond on the neighbouring phosphorus atom [4].

We examine several possible $\mathrm{Be}-\mathrm{H}$ complexes in $\mathrm{InP}$ in order to determine the lowest-energy structure and the passivation mechanism of the hydrogen.

\section{Method}

The calculations used here are $a b$ initio local density functional pseudopotential ones carried out on large $\mathrm{H}$ terminated clusters using the serial version of the AIMPRO code (described in detail elsewhere [9]). The electronic wavefunctions are expanded in s and p Gaussian orbitals centred at nuclei as well as at bond centres. Normconserving pseudopotentials [10] are used in order to exclude core electrons. The self-consistent energy $E$ and the force on each atom are calculated and the atoms moved by a conjugate gradient algorithm to equilibrium.

Throughout this paper, a fixed notation is used to indicate the basis sets used to model each atom type. Each atom requires a number of Gaussian basis functions for the wavefunction and charge density. $A(n, m)$ indicates that for atom type $A$ we used $n$ wavefunction basis functions and $m$ charge-density basis functions. In the text we describe additional Gaussian basis functions which are placed on bond centres to allow more accurate modelling. These basis functions make it unnecessary to include $d$ orbitals sited at the In atomic sites.

Initial calculations on pure InP used an 86-atom bond centred cluster, $\mathrm{In}_{22} \mathrm{P}_{22} \mathrm{H}_{42}$ with $\mathrm{C}_{3 \mathrm{v}}$ symmetry. We fitted a Musgrave-Pople interatomic potential to the pure InP dynamical matrix and used this to determine the bulk phonon modes. The basis sets used were $\operatorname{In}(8,8), \mathrm{P}(8,8)$ and $\mathrm{H}(2,3)$, with bond-centred fitting functions on all of the bonds between the inner eight atoms. Symmetry was maintained at $\mathrm{C}_{3 \mathrm{v}}$ throughout.

In order to examine the hydrogenated vacancies, we generated a 131-atom hydrogen-terminated InP cluster, $\mathrm{In}_{31} \mathrm{P}_{40} \mathrm{H}_{60}$. The central $\mathrm{In}$ atom was replaced by up to four hydrogen atoms (see figure 1). Symmetry was only enforced for $\mathrm{V}_{\mathrm{In}} \mathrm{H}_{4}^{+}\left(\mathrm{T}_{\mathrm{d}}\right)$. Two electrons were added for each bond, so the resultant cluster charge was +9. In order to keep the cluster charge constant, the structures optimized were $\mathrm{V}_{\text {In }} \mathrm{H}_{4}^{+}, \mathrm{V}_{\text {In }} \mathrm{H}_{3}, \mathrm{~V}_{\text {In }} \mathrm{H}_{2}^{-}, \mathrm{V}_{\text {In }} \mathrm{H}^{2-}$ and $\mathrm{V}_{\mathrm{In}}^{3-}$. The electronic spin component was averaged.

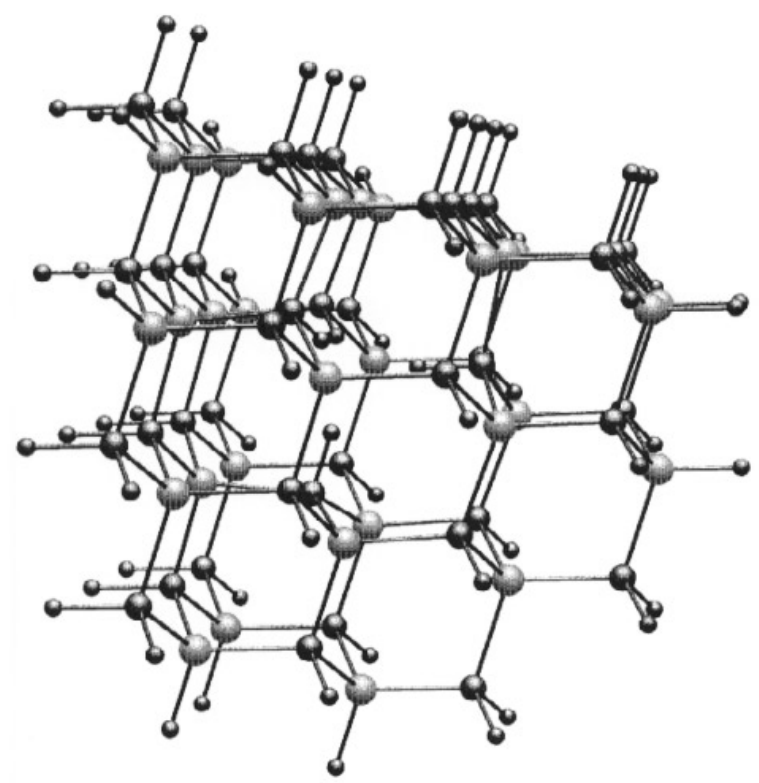

Figure 1. The 134-atom cluster $\ln _{30} \mathrm{P}_{40} \mathrm{H}_{64}$ containing the defect $\mathrm{V}_{\text {In }} \mathrm{H}_{4}^{+}$.

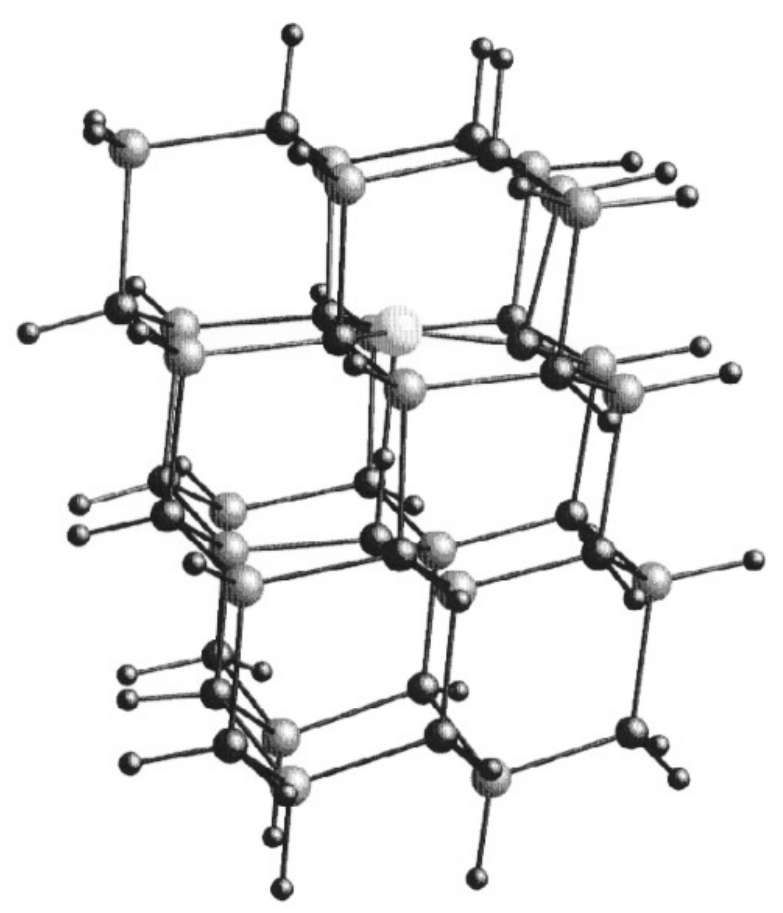

Figure 2. The 88-atom cluster Beln ${ }_{21} \mathrm{P}_{22} \mathrm{H}_{43}$.

The basis sets used were $\operatorname{In}(8,8), \mathrm{P}(4,5)$ and $\mathrm{H}(2,3)$. Bondcentred Gaussians were placed on the twelve In-P bonds neighbouring the vacancy.

For examination of the $\mathrm{Be}-\mathrm{H}$ complexes we generated an 86-atom hydrogen-terminated InP cluster, $\operatorname{In}_{22} \mathrm{P}_{22} \mathrm{H}_{42}$. This is In-P bond centred. The centre In atom was replaced with $\mathrm{Be}$, and $\mathrm{a} \mathrm{H}$ atom inserted at one of three different sites: antibonded behind the $\mathrm{Be}$, antibonded behind the $\mathrm{P}$, and in the bond centre between $\mathrm{Be}$ and $\mathrm{P}$. This resulted 
Table 1. Phonon frequencies for pure $\operatorname{lnP}\left(\mathrm{cm}^{-1}\right)$.

\begin{tabular}{llllll}
\hline Location & Mode & $\begin{array}{l}\text { Neutron diffraction } \\
(300 \mathrm{~K})[15]\end{array}$ & $\begin{array}{l}\text { Raman scattering } \\
(300 \mathrm{~K})[16]\end{array}$ & $\begin{array}{l}\text { Far IR } \\
(20 \mathrm{~K})[12]\end{array}$ & \begin{tabular}{l} 
Theoretical \\
\hline$\Gamma(0,0,0)$
\end{tabular} \\
& LO & & 345.4 & 351 & 354.80 \\
& TO & $307 \pm 7$ & 303.3 & & 354.80 \\
$\mathrm{X}(1,0,0)$ & LO & $332 \pm 3$ & & 328.5 & 324.59 \\
& TO & $324 \pm 7$ & & 326.5 & 317.46 \\
& LA & $194 \pm 10$ & & 190.5 & 186.86 \\
& TA & $68 \pm 3$ & & 67.5 & 69.59 \\
$\mathrm{~L}\left(\frac{1}{2}, \frac{1}{2}, \frac{1}{2}\right)$ & LO & $340 \pm 10$ & & 340.5 & $335.27(5,6)$ \\
& TO & $317 \pm 5$ & & 315.5 & $314.03(4)$ \\
& LA & $167 \pm 3$ & & 167.5 & 171.19 \\
& TA & $55.0 \pm 0.7$ & & 53.5 & 49.49 \\
\hline
\end{tabular}

in the cluster $\mathrm{BeIn}_{21} \mathrm{P}_{22} \mathrm{H}_{43}$ (see figure 2). Symmetry was constrained to be $C_{3 v}$. The basis sets used were $\operatorname{In}(8,8)$ and $\mathrm{P}(8,8)$ for the seven core $\operatorname{InP}$ atoms, $\operatorname{In}(4,5)$ and $\mathrm{P}(4,5)$ for the rest, $\operatorname{Be}(6,6)$ and $\mathrm{H}(3,4)$. Bond-centred Gaussians were placed between the inner nine atoms.

The eigenvalues calculated here are Kohn-Sham eigenvalues, and are not directly comparable with experimental eigenvalues. LDF theory tends to underpredict bandgaps, whereas finite cluster sizes broaden them. Thus these calculated eigenvalues indicate qualitatively whether defect levels lie in the gap, but are only quantitatively useful when comparing similar clusters.

\section{Pure InP}

Initial investigations centred on pure InP, in order to determine vibrational frequencies and a phonon dispersion curve, and to obtain a set of Musgrave-Pople interatomic potentials for frequency calculations in the defect clusters.

After relaxation, we obtained central InP bond lengths of $2.480 \AA$ along the $\langle 111\rangle$ axis parallel to the $\mathrm{C}_{3 \mathrm{v}}$ axis, and $2.421 \AA$ otherwise (errors of $2.4 \%$ and $4.7 \%$ respectively, as the experimental bond length is $2.54 \AA$ [11]). The bond elongation in the (111) direction is due to the intrinsic dipole moment of a bond-centred cluster. The nearestneighbour $\mathrm{P}-\mathrm{In}-\mathrm{P}$ bond angle was $111.5^{\circ}$, and $107.3^{\circ}$ when using the In-P bond parallel to the $\mathrm{C}_{3 \mathrm{v}}$ axis; these are within $2^{\circ}$ of the tetrahedral angle.

A supercell calculation of the full phonon dispersion curve was performed using the Musgrave-Pople interatomic potential. This is given in figure 3 along with various experimental values. Selected values from this curve are given in table 1 . We do not obtain any LO-TO splitting because of an absence of long-range electric field effects in the potential. The highest bulk phonon modes are 354.80 (351), 324.59 (328.5), and $335.27 \mathrm{~cm}^{-1}\left(340.5 \mathrm{~cm}^{-1}\right)$ at $\Gamma$, $\mathrm{X}$, and $\mathrm{L}$ respectively (the experimental modes at $20 \mathrm{~K}$ are in brackets [12]); thus our frequency errors are $\approx 4 \mathrm{~cm}^{-1}$. The calculated bandgap for InP was $0.84 \mathrm{eV}$, compared to an experimental value of $1.34 \mathrm{eV}$ deduced from optical data [13], and is in good agreement with a previous LDF value of $0.8 \mathrm{eV}$ [14] (see section 2 above). Our calculated

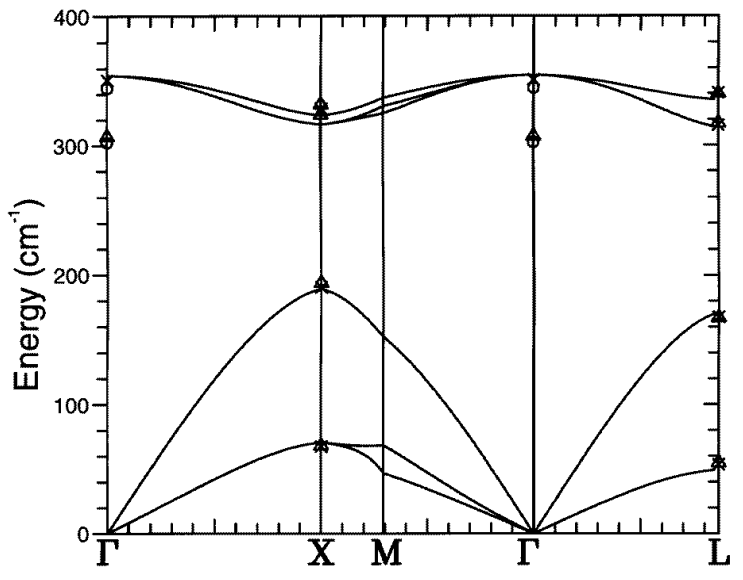

Figure 3. The calculated phonon dispersion curve for $\ln P$.

Table 2. Calculated LVMs for the fully hydrogenated vacancy in $\operatorname{InP}, \mathrm{V}_{\mathrm{In}} \mathrm{H}_{n} \mathrm{D}_{m}^{+}, n+m=4$. The asterisk indicates IR inactive; $T$ indicates triplet and $\mathrm{D}$, doublet.

\begin{tabular}{llrlr}
\hline $\mathrm{H}_{4}$ & $\mathrm{H}_{3} \mathrm{D}$ & \multicolumn{1}{c}{$\mathrm{H}_{2} \mathrm{D}_{2}$} & \multicolumn{1}{l}{$\mathrm{HD}_{3}$} & \multicolumn{1}{l}{$\mathrm{D}_{4}$} \\
\hline $2387.85^{*}$ & 2380.18 & 2372.34 & 2364.31 & $1713.01^{*}$ \\
$2356.40 \mathrm{~T}$ & $2356.32 \mathrm{D}$ & 2356.24 & 1707.26 & $1690.82 \mathrm{~T}$ \\
$618.57 \mathrm{D}$ & 1696.43 & 1701.74 & $1690.95 \mathrm{D}$ & $445.34 \mathrm{D}$ \\
$565.87 \mathrm{~T}$ & $603.12 \mathrm{D}$ & 1691.08 & $549.65 \mathrm{D}$ & $411.94 \mathrm{~T}$ \\
$408.69 \mathrm{~T}$ & 565.71 & 595.02 & $428.92 \mathrm{D}$ & \\
& $508.72 \mathrm{D}$ & 556.04 & 412.03 & \\
& 408.69 & 541.80 & & \\
& & 481.28 & & \\
& & 425.83 & & \\
& & &
\end{tabular}

bandgap is underestimated, which is unusual for a cluster calculation.

We conclude that our method gives bond lengths and local vibrational modes within an acceptable error range.

\section{Hydrogenated vacancy centres}

The local vibrational modes for $\mathrm{V}_{\text {In }} \mathrm{H}_{4}$ with pure and mixed isotope compositions are shown in table 2. The highest 


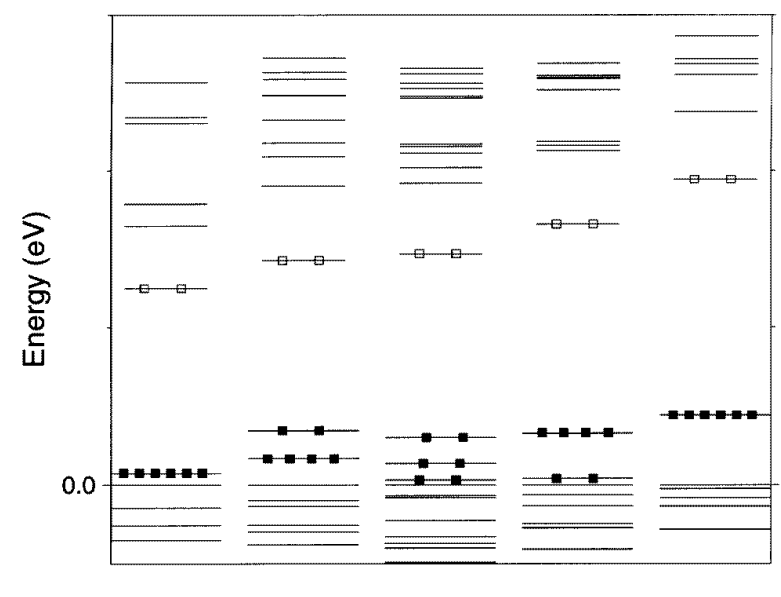

(a) (b) (d)

Figure 4. The top Kohn-Sham eigenvalues of the hydrogenated vacancies; (a) $\mathrm{V}_{\text {In }} \mathrm{H}_{4}^{+}$, (b) $\mathrm{V}_{\text {In }} \mathrm{H}_{3}$, (c) $\mathrm{V}_{\text {In }} \mathrm{H}_{2}^{-}$, (d) $\mathrm{V}_{\mathrm{In}} \mathrm{H}^{2-}$, (e) $\mathrm{V}_{\mathrm{In}}^{3-}$. Filled boxes indicate electrons and empty boxes indicate holes. The eigenvalues have been arbitrarily shifted to align the highest filled level below the $\mathrm{t}_{2}$-like state with zero.

IR visible mode for $\mathrm{V}_{\text {In }} \mathrm{H}_{4}^{+}$at $2356.4 \mathrm{~cm}^{-1}$ is in excellent agreement with experiment $\left(2315.6 \mathrm{~cm}^{-1}\right.$, a $1.8 \%$ error $)$, as is the $1690.8 \mathrm{~cm}^{-1}$ mode for $\mathrm{V}_{\mathrm{In}} \mathrm{D}_{4}^{+}$(experimental value of $1683.4 \mathrm{~cm}^{-1}$, an error of $0.4 \%$ ). This small drop in error with deuteration suggests only limited anharmonic character in the bonding [17].

The LVMs for the range of hydrogenated vacancies, $\mathrm{V}_{\text {In }} \mathrm{H}_{n}, n=0,4$, are shown in table 3 . The results show that as the number of $\mathrm{H}$ atoms in the vacancy increases, the $\mathrm{P}$ $\mathrm{H}$ bonds are shortened and the frequency of the vibrational modes increases. This is due to the compressive effect of the other hydrogen atoms on each $\mathrm{P}-\mathrm{H}$ group, coupled with the removal of dangling bonds from 'unsaturated' $\mathrm{P}$ atoms which would have acted to attract the hydrogen away from its phosphorus neighbour. This is consistent with previous results obtained for $\mathrm{Si}[5,18]$.

The shift in $\mathrm{P}-\mathrm{H}$ length from $\mathrm{V}_{\text {In }} \mathrm{H}_{4}$ to $\mathrm{V}_{\text {In }} \mathrm{H}$ is only $2.1 \%$ (from $1.419 \AA$ to $1.450 \AA$ ), but it leads to a $9.9 \%$ shift in vibrational mode $\left(2387.8 \mathrm{~cm}^{-1}\right.$ to $\left.2150.7 \mathrm{~cm}^{-1}\right)$. The calculated $\mathrm{H}$ stretch modes of the partially hydrogenated vacancies could account for a group of experimentally observed vibrational modes lying between 2200 and $2290 \mathrm{~cm}^{-1}[4,19]$.

The top Kohn-Sham eigenvalues of the hydrogenated vacancies are shown in figure 4. In each case there is a $t_{2}$-like state above the top of the valence band which splits as the number of $\mathrm{H}$ atoms decreases, and a singlet state near to the conduction band. In the fully hydrogenated neutral vacancy, $\mathrm{V}_{\mathrm{In}} \mathrm{H}_{4}$, the singlet is partially occupied, and therefore acts as a donor.

As each hydrogen atom is removed from the vacancy, an electron is removed from the highest occupied state. The resulting defects can act as acceptors that fill the $t_{2}$ level when ionized. This level is already filled in the case of $\mathrm{V}_{\text {In }} \mathrm{H}_{3}$ so this defect cannot act as an acceptor. However, $\mathrm{V}_{\text {In }} \mathrm{H}_{2}, \mathrm{~V}_{\text {In }} \mathrm{H}$ and $\mathrm{V}_{\text {In }}$ will behave as single, double and triple acceptors respectively.

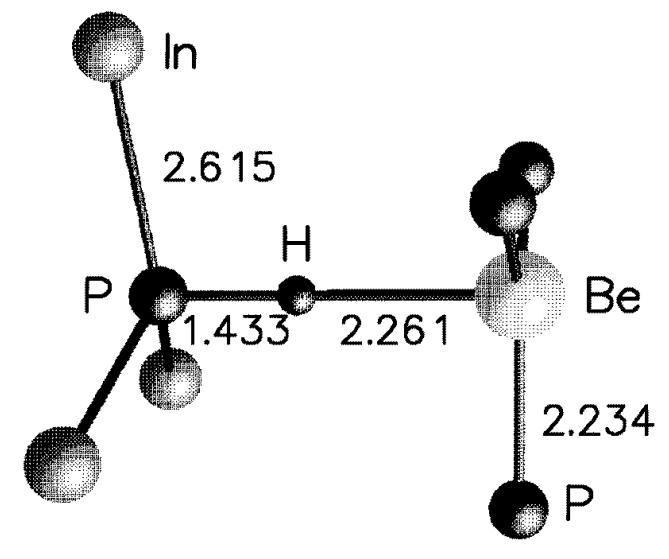

Figure 5. The calculated structure for $\mathrm{H}$-passivated $\mathrm{Be}$ in InP (the bond lengths are in $\AA$ ).

The $t_{2}$ level is split due to the lower symmetry of the partially hydrogenated vacancies. $\mathrm{V}_{\mathrm{In}} \mathrm{H}_{4}^{+}$has $\mathrm{T}_{\mathrm{d}}$ symmetry and therefore the level does not split. $\mathrm{V}_{\mathrm{In}} \mathrm{H}_{3}$ has $\mathrm{C}_{3 \mathrm{v}}$ symmetry, so the $t_{2}$ level splits into an $e$ and an $a_{1}$ level. $\quad \mathrm{V}_{\mathrm{In}} \mathrm{H}_{2}^{-}$has $\mathrm{C}_{2 \mathrm{v}}$ symmetry which leads to three separated singlets. $\mathrm{V}_{\mathrm{In}} \mathrm{H}^{2-}$ and $\mathrm{V}_{\mathrm{In}}^{3-}$ are directly comparable with $\mathrm{V}_{\text {In }} \mathrm{H}_{3}$ and $\mathrm{V}_{\text {In }} \mathrm{H}_{4}^{+}$, with the dangling and hydrogenterminated bonds reversed, in addition to the a-e level ordering. This $t_{2}$-like state gradually moves upwards away from the valence band as hydrogen atoms are removed. In $\mathrm{V}_{\text {In }}^{3-}$ the $\mathrm{t}_{2}$ level is quite deep in the gap.

The indium vacancy, $\mathrm{V}_{\mathrm{In}}^{3-}$, fits the trend of increasing acceptor character with a decreasing number of hydrogen atoms present. Previous calculations [20] also show $\mathrm{V}_{\text {In }}$ to be a triple acceptor.

High-temperature annealing of InP:Fe reduces the concentration of $\mathrm{V}_{\mathrm{In}} \mathrm{H}_{4}^{+}$. This is due to the partial dissociation of this centre and, up until now, only $\mathrm{V}_{\text {In }} \mathrm{H}$ has been identified with certainty. It is shown here that $\mathrm{V}_{\text {In }} \mathrm{H}_{2}$ and $\mathrm{V}_{\mathrm{In}} \mathrm{H}$ are acceptors. In annealed high-resistivity material they should cause a drop in the $\mathrm{Fe}^{2+}$ concentration. This will be in addition to the decrease in concentration of $\mathrm{Fe}^{2+}$ due to loss of the $\mathrm{V}_{\mathrm{In}} \mathrm{H}_{4}$ donor.

In contrast, von Bardeleben et al [21] found that thermal annealing of Fe-doped $\mathrm{InP}$ in the range $660-820{ }^{\circ} \mathrm{C}$ led to an increase in $\mathrm{Fe}^{2+}$ concentration. They suggested that this was due to the formation of some unidentified deep thermal donors. This could be associated with other hydrogen complexes. However, from this work it seems unlikely that hydrogenated vacancies are responsible.

In summary, the fully hydrogenated vacancy, $\mathrm{V}_{\mathrm{In}} \mathrm{H}_{4}$, acts as a single donor due to a partially filled singlet near the top of the gap; thus $\mathrm{V}_{\mathrm{In}} \mathrm{H}_{4}$ will compensate $\mathrm{Fe}_{\mathrm{In}}^{3+}$ in InP. Removal of hydrogen atoms from the vacancy leads to increased acceptor character as the triplet state starts to empty.

\section{Passivation of group II impurities}

Be was used to determine the preferential site for hydrogen in the passivated group II acceptor-hydrogen complex. In order to maintain $\mathrm{C}_{3 \mathrm{v}}$ symmetry along the (111) axis, 
Table 3. The local vibrational modes $\left(\mathrm{cm}^{-1}\right)$, symmetry, and calculated bond lengths $(\AA)$ of hydrogenated vacancies in InP. The asterisk indicates IR inactive; $T$ indicates triplet and $D$, doublet.

\begin{tabular}{|c|c|c|c|c|c|c|c|}
\hline \multirow[b]{2}{*}{ Defect } & \multicolumn{5}{|c|}{ Local vibrational modes } & \multirow[b]{2}{*}{ Symmetry } & \multirow{2}{*}{$\begin{array}{l}\text { Bond } \\
\text { length }\end{array}$} \\
\hline & Experiment [6] & [4] ([19]) & & Calculation & & & \\
\hline $\mathrm{V}_{\ln \mathrm{H}_{4}^{+}}$ & 2315.2 & 2315.6 & 2387.8 * & $2356.4 \mathrm{~T}$ & $618.6 \mathrm{D}$ & $T_{d}$ & 1.419 \\
\hline $\mathrm{V}_{\ln \mathrm{D}_{4}^{+}}$ & 1683.4 & & 1713.0 * & $1690.8 \mathrm{~T}$ & $445.3 \mathrm{D}$ & & \\
\hline $\mathrm{V}_{\ln } \mathrm{H}_{3}$ & & & 2324.1 & $2286.3 \mathrm{D}$ & 695.3 D & $\mathrm{C}_{3 \mathrm{v}}$ & 1.429 \\
\hline$V_{\text {In }} D_{3}$ & & & 1667.6 & $1640.8 \mathrm{D}$ & $498.2 \mathrm{D}$ & & \\
\hline $\mathrm{V}_{\mathrm{In}} \mathrm{H}_{2}^{-}$ & & & $\begin{array}{r}2256.2 \\
617.7\end{array}$ & $\begin{array}{r}2216.8 \\
611.8\end{array}$ & $\begin{array}{l}730.0 \\
602.0\end{array}$ & $\mathrm{C}_{2 \mathrm{v}}$ & 1.439 \\
\hline $\mathrm{V}_{\ln } \mathrm{D}_{2}^{-}$ & & & $\begin{array}{r}1619.4 \\
446.4\end{array}$ & $\begin{array}{r}1591.6 \\
444.4\end{array}$ & $\begin{array}{l}523.0 \\
438.8\end{array}$ & & \\
\hline $\mathrm{V}_{\text {In }} \mathrm{H}^{2-}$ & 2201.7 & (2202.4) & 2150.7 & 644.9 & 644.7 & $\mathrm{C}_{3 \mathrm{v}}$ & 1.450 \\
\hline $\mathrm{V}_{\ln } \mathrm{D}^{2-}$ & 1603.8 & & 1544.7 & 467.5 & 467.4 & & \\
\hline
\end{tabular}

Table 4. Calculated and experimental LVMs for $\mathrm{H}$-passivated $\mathrm{Be}$ in $\ln \mathrm{P}\left(\mathrm{cm}^{-1}\right)$.

\begin{tabular}{|c|c|c|c|c|c|}
\hline \multicolumn{2}{|c|}{ Experimental } & \multicolumn{2}{|c|}{ Bond centred } & \multicolumn{2}{|c|}{ Antibonded behind $P$} \\
\hline $\mathrm{H}$ & $\mathrm{D}$ & $\mathrm{H}$ & $\mathrm{D}$ & $\mathrm{H}$ & $\mathrm{D}$ \\
\hline 2236.5 & 1630.9 & 2287.71 & 1639.90 & 2469.85 & 1770.94 \\
\hline
\end{tabular}

hydrogen can sit at one of only three sites: at the P-Be bond centre, or one of the two antibonded sites behind $\mathrm{P}$ or Be (see figure 5).

The structure with $\mathrm{H}$ lying in an antibonded site behind Be was $1.77 \mathrm{eV}$ higher in energy than in the bond-centred case, and so was energetically unfavourable. The structure with $\mathrm{H}$ antibonded behind $\mathrm{P}$ was only $0.13 \mathrm{eV}$ higher in energy than the bond-centred case, close to the expected errors in our calculation. In all cases the gap was cleared of any acceptor levels by the presence of the hydrogen atom, showing that it has passivated the acceptor activity. In order to determine whether the bond-centred or 'antibonded behind P' model is correct, it is necessary to examine the LVMs, shown in table 4.

As can be seen, the calculated LVMs for the bondcentred case are in good agreement with experiment (errors of $2.3 \%$ and $0.6 \%$ for $\mathrm{H}$ and $\mathrm{D}$ respectively) whereas the results from antibonding are poor $(10.4 \%$ and $8.6 \%$ for $\mathrm{H}$ and $\mathrm{D}$ respectively). From this we conclude that the preferential $\mathrm{H}$ site is at the bond-centred location.

The defect is shown in figure 5. The large $\mathrm{H}-\mathrm{Be}$ separation shows a lack of bonding between $\mathrm{H}$ and $\mathrm{Be}$; the $\mathrm{H}$ atom is strongly bonded to $\mathrm{P}$. The $\mathrm{P}-\mathrm{H}$ bond length is comparable to the $\mathrm{P}-\mathrm{H}$ bond lengths in the hydrogenated vacancy, and compares to an experimental bond length for the $\mathrm{P}-\mathrm{H}_{3}$ molecule of $1.43 \AA$ [11]. The $\mathrm{Be}-\mathrm{P}$ bond lengths are similar to crystalline $\mathrm{Be}-\mathrm{P}$ lengths in $\mathrm{Be}_{3} \mathrm{P}_{2}(2.16 \AA)$. The impurity is displaced along the $\langle 111\rangle$ direction away from the hydrogen atom to achieve this, until it is coplanar with the phosphorus atoms.

Therefore we conclude that substitutional Be acceptors are passivated by a single $\mathrm{H}$ sitting at a bond-centred position between the $\mathrm{Be}$ atom and a nearest-neighbour $\mathrm{P}$ atom. We find a LVM at $2287.71 \mathrm{~cm}^{-1}, 2.3 \%$ larger than the experimental frequency. There is also an undetected wag mode at $644 \mathrm{~cm}^{-1}$, similar to that of the $\mathrm{C}-\mathrm{H}$ defect in GaAs and AlAs [17, 22]. Work is currently under way to determine whether this behaviour is typical of other group II acceptor atoms in InP.

\section{Conclusions}

Our conclusions are as follows.

(1) Our LDF calculations predict the highest bulk phonon modes in pure InP to be 354.80 (351), 324.59 (328.5), and $335.27 \mathrm{~cm}^{-1}\left(340.5 \mathrm{~cm}^{-1}\right)$ at $\Gamma, X$, and $\mathrm{L}$ respectively (the experimental modes at $20 \mathrm{~K}$ are in brackets [12]); thus our frequency errors are $4 \mathrm{~cm}^{-1}$. The error in bond length for pure $\mathrm{InP}$ is $4.1 \%$.

(2) $\mathrm{V}_{\mathrm{In}} \mathrm{H}_{4}$ is shown to be a single donor forming $\mathrm{V}_{\text {In }} \mathrm{H}_{4}^{+}$, with a donor level in the upper part of the gap. $\mathrm{V}_{\mathrm{In}} \mathrm{H}_{3}$ is shown to be electrically inactive, but the partially hydrogenated vacancies, $\mathrm{V}_{\text {In }} \mathrm{H}_{2}$ and $\mathrm{V}_{\text {In }} \mathrm{H}$, act as acceptors, forming $\mathrm{V}_{\mathrm{In}} \mathrm{H}_{2}^{-}$and $\mathrm{V}_{\mathrm{In}} \mathrm{H}^{2-}$ with acceptor levels in the lower gap region.

(3) $\mathrm{V}_{\mathrm{In}} \mathrm{H}_{4}$ compensates $\mathrm{Fe}_{\mathrm{In}}^{3+}$ leading to the formation of $\mathrm{Fe}_{\mathrm{In}}^{2+}$. The donor electron could also be trapped by the partially hydrogenated vacancy centres, $\mathrm{V}_{\mathrm{In}} \mathrm{H}_{2}^{-}$, and $\mathrm{V}_{\text {In }} \mathrm{H}^{2-}$, or even $\mathrm{V}_{\text {In }}^{3-}$; however, these are present in much lower concentrations than is $\mathrm{V}_{\text {In }} \mathrm{H}_{4}^{+}$.

(4) The P-H bond length in the hydrogenated vacancy centres becomes shorter as more hydrogen atoms are added to the vacancy. This causes a corresponding increase in the hydrogen local vibrational modes.

(5) The H-related LVMs have been calculated for both the fully and partially hydrogenated vacancies. Darwich et al [4] have observed a number of vibrational modes in their InP:Fe samples between $2202.39 \mathrm{~cm}^{-1}$ and $2282.8 \mathrm{~cm}^{-1}$ which have been attributed to H-related complexes [8], and we suggest that the partially hydrogenated vacancy centres could account for at least some of these modes. 
(6) In agreement with experiment, the calculations show that $\mathrm{H}$ is able to passivate group II acceptors such as Be. It lies, bond centred, between $\mathrm{Be}$ and $\mathrm{P}$, and forms a strong bond with $\mathrm{P}$ rather than $\mathrm{Be}$.

(7) $\mathrm{H}$ in the bond-centred and two possible antibonding sites (behind $\mathrm{P}$ or $\mathrm{Be}$ ) always passivates the $\mathrm{Be}$ atom. However, the antibonding behind $\mathrm{Be}$ is $1.77 \mathrm{eV}$ higher in energy than the bond-centred case, and only the bondcentred site produces the correct LVMs. From this we conclude that the $\mathrm{H}$ atom must lie bond centred, between $\mathrm{Be}$ and $\mathrm{P}$.

(8) The Be moves off-site along the $\langle 111\rangle$ axis until it lies coplanar with its three $\mathrm{P}$ neighbours. This allows it to form stronger, more molecular-like bonds with the $\mathrm{P}$ atoms.

\section{Acknowledgments}

SÖ thanks NFR and TFR in Sweden for financial support. $\mathrm{He}$ also thanks PDC at KTH in Sweden, for time on the SP2. We also thank the HPCI committee of the EPSRC for the computer time on the T3D used to obtain some of these results.

\section{References}

[1] Mizuno O and Watanabe H 1975 Electron. Lett. 11118

[2] Carnera A, Gasparotto A, Tromby M, Caldironi M, Pellegrino S, Vidimari F, Bocchi C and Frigeri C 1994 J. Appl. Phys. 769

[3] Zach F X 1994 J. Appl. Phys. 7512

[4] Darwich R, Pajot B, Rose B, Robein D, Theys B, Rahbi R, Porte C and Gendron F 1993 Phys. Rev. B 4824
[5] Bech Neilsen B, Berg Rasmussen F, Hoffmann L, Budde M, Jones R, Goss J and Öberg S 1995 Mater. Sci. Forum 196-201 933-8

[6] Fischer D W, Manasreh M O and Matous G 1992 J. Appl. Phys. 714805

[7] Pantelides S T 1975 Festkörperprobleme (Advances in Solid State Physics) vol 15, ed P Grosse (New York: Pergamon) p 149

[8] Chevallier J, Clerjaud B and Pajot B 1991 Hydrogen in Semiconductors ed J I Pankove and N M Johnson (Orlando, FL: Academic)

[9] Jones R 1992 Phil. Trans. R. Soc. A 341351

[10] Bachelet G B, Hamann D R and Schlüter M 1982 Phys. Rev. B 264199

[11] Slater J 1965 Quantum Theory of Molecules and Solids vol 2 (New York: McGraw-Hill)

[12] Koteles E S and Datars W R 1976 Solid State Commun. 19 221

[13] Folberth O G and Weiss H 1955 Z. Naturf. a 10615

[14] Khowash P K 1994 Phys. Rev. B 4916

[15] Borcherds P H, Alfrey G F, Saunderson D H and Woods A D B 1975 J. Phys. C: Solid State Phys. 82022

[16] Hilsum C, Fray S J and Smith C 1969 Solid State Commun. 71057

[17] Jones R, Goss J, Ewels C P and Öberg S 1994 Phys. Rev. B 508378

[18] Roberson M A and Estreicher S K 1994 Phys. Rev. B 49 17040

[19] Clerjaud B, Côte D and Naud C 1987 Phys. Rev. Lett. 58 1755; J. Cryst. Growth 83190

[20] Seitsonen A P, Virkkunen R, Puska M J and Nieminen R M 1994 Phys. Rev. B 495253

[21] von Bardeleben H J, Stievenard D, Kainosho K and Oda O 1991 J. Appl. Phys. 707392

[22] Pritchard R, Davidson B R, Newman R C, Bullough T J, Joyce T B, Jones R and Öberg S 1994 Semicond. Sci. Technol. 9140 